RESENHA

\title{
Abuso sexual infantil: esforços necessários para acabar com essa violência
}

\section{Child sexual abuse: what are the necessary steps to end the violence?}

\section{Luciana Cristina Assini*}

Universidade Federal de Santa Catarina, Florianópolis, Santa Catarina, Brasil

\section{Sílvio Paulo Botomé**}

Universidade Federal de Santa Catarina, Florianópolis, Santa Catarina, Brasil

WI LLIAMS, L. C. A.; ARAÚJO, E. A. C. (Orgs.). Prevenção do abuso sexual infantil: um enfoque interdisciplinar. Curitiba: Juruá, 2009, $234 p$.

O abuso sexual, com todas as consequências que pode deixar para suas vítimas, tem mais responsáveis que apenas o próprio agressor. Os profissionais dos campos de atuação responsáveis por impedir a ocorrência do abuso também participam de seu acontecimento. Quais os esforços que profissionais da área da Saúde, Educação, Justiça, Segurança Pública têm feito para impedir a ocorrência desse tipo de violência ou, em casos já sucedidos, de intervir de modo a minimizar os danos causados às vítimas? Quão adequados ou eficazes têm sido esses esforços? Quantos deles estão orientados para prevenir a ocorrência do abuso sexual infantil? Um debate a respeito disso está apresentado no livro "Prevenção do abuso sexual infantil: um enfoque multidisciplinar" organizado por Lúcia Cavalcanti Albuquerque Williams e Eliane Aparecida Campanha Araújo. O livro é constituído pelas palestras apresentadas no I Encontro Internacional sobre Violência na Família ocorrido em 2007 na cidade de São Carlos (SP), com tema específico relacionado ao abuso sexual infantil.

A obra revela de que maneira profissionais de diferentes áreas de atuação têm lidado com esse fenômeno e quais os desafios a serem superados para diminuir o número de crianças e adolescentes vítimas desse tipo de violência. Por essas características o conjunto de capítulos dessa obra merece ser lido por profissionais que lidam direta ou indiretamente com esse fenômeno. A obra ajuda a aumentar a visibilidade de vários aspectos importantes relacionados à atuação profissional nos acontecimentos de abuso sexual infantil ou nas situações que indicam probabilidade de ocorrência desse tipo de abuso contra crianças. 
Um dos primeiros aspectos de destaque dessa obra é ser o registro dos trabalhos apresentados em um Encontro Profissional Internacional. Isso auxiliou a ser um livro repleto de informações atuais acerca de dados produzidos por meio de pesquisa e intervenções profissionais com crianças e adolescentes que sofreram abuso sexual. Por ter sido um encontro internacional, os trabalhos que o livro contém trazem a possibilidade de comparar as intervenções de profissionais de diferentes países, enriquecendo muito a percepção do que está sendo feito a respeito do problema do abuso sexual com crianças e adolescentes. Em alguns trabalhos, há o registro de endereços eletrônicos que podem ser acessados pelos leitores que queiram conferir em mais detalhes 0 que esses profissionais estão realizando. Outra característica relevante, por tratar-se de um livro elaborado a partir do que foi apresentado em um Encontro Internacional, é apresentar as propostas dos grupos de trabalho realizadas no próprio Encontro. Isso possibilita o acesso ao leitor do exame e avaliação de alternativas ao enfrentamento do abuso sexual infantil, resultantes de três dias de debates de profissionais que trabalham com esse tipo de problema na sociedade, em contextos variados e procedimentos diversificados de intervenção. Cabe destacar, ainda, que a obra retrata a experiência profissional de psicólogos, promotores de justiça, juiz e assistente social com o abuso sexual infantil, sendo esses, em sua maioria, brasileiros. Tal condição possibilita observar as peculiaridades e as dificuldades da atuação profissional em casos de abuso nas condições dos serviços públicos existentes no Brasil - o que torna esse livro uma obra particularmente relevante para profissionais brasileiros. A facilidade ou a dificuldade para intervir nas condições que se relacionam com o abuso sexual estão fortemente vinculadas às políticas públicas que regulam os serviços oferecidos por meio da Saúde, Justiça, Segurança e Assistência Social e às condições para esses profissionais atuarem em cada país.

Algumas das características da situação do Brasil quanto ao enfrentamento do abuso sexual infantil estão examinadas no capítulo "Panorama internacional e a posição do Brasil no enfrentamento e prevenção do abuso sexual infantil". Entre os problemas examinados pela autora deste capítulo (Victoria Lidchi) está a baixa ocorrência de comunicação entre profissionais de diferentes serviços existentes no país. Esse exame é corroborado no capítulo "O papel do WCF-Brasil (World Childhood Foundation) na prevenção do abuso sexual infantil". De acordo com Margarete Santos Marques (a autora desse capítulo), uma das maiores queixas entre os profissionais que trabalham com crianças vítimas de abuso é a falta de comunicação entre os profissionais que compõem a rede de atendimento a essas crianças. Paradoxalmente, a multidisciplinaridade é um dos fatores cruciais na prevenção e no atendimento a crianças que sofrem abuso sexual e, 
ao mesmo tempo, um dos maiores desafios a ser superado para evitar ou impedir a ocorrência desse tipo de problema social altamente lesivo.

Especificamente em relação ao sistema judiciário, o exame dos aspectos apresentados no livro destaca a ineficiência em punir agressores nos casos denunciados ao poder público. Os dados examinados na obra de Williams e Araújo mostram que a maioria dos casos denunciados terminam em arquivamento sem providências específicas quanto ao abuso sexual ou seus determinantes ou agentes que os realizam. A respeito de "O papel do sistema judiciário na prevenção do abuso sexual infantil" (capítulo escrito por João Batista Galhardo Júnior), o autor afirma que, no Brasil, os dispositivos legais para julgamento dos casos de abuso são frágeis. Eles contribuem para a situação nomeada pelo autor de "impunidade generalizada". Essa impunidade também foi retratada por meio de dados apresentados por Williams no capítulo introdutório do livro. De acordo com a autora, em uma pesquisa realizada na cidade de São Carlos (SP), em 2003, entre 37 denúncias registradas apenas uma resultou em condenação. Mesmo assim, essa consistiu apenas no pagamento de uma multa de $R \$ 86,00$. Esse é um dado alarmante, que acarreta a perda da oportunidade de oferecer ou mesmo exigir tratamento psicológico ao agressor. Uma consequência social fortemente prejudicial é aumentar a probabilidade de perpetuação da violência em função de não existirem ações adequadas à coação ou prevenção desse tipo (ou classe) de comportamentos na sociedade.

Ao longo dos demais capítulos do livro são apresentadas características peculiares dos comportamentos das vítimas, que exigem desempenhos sofisticados dos profissionais que lidam com esse fenômeno. Isso é especialmente destacado no capítulo, "A escuta de crianças abusadas sexualmente para compreensão do processo de revelação" (autoria de Alison Cunningham), em que são apresentados dados de pesquisas realizadas no Centro para Crianças e Famílias do Sistema Judiciário do Canadá, do qual a autora é diretora. Esses dados esclarecem vários comportamentos característicos do processo de revelação. Destaque-se a importância desses dados uma vez que o comportamento da vítima de revelar o que aconteceu é uma classe de comportamento de alta complexidade e cuja aprendizagem, desenvolvimento ou aperfeiçoamento ocorre exatamente em condições muito difíceis, depois de ter sido submetida a uma experiência aversiva e, ao ter que apresentar esse comportamento, ser obrigada a lidar de novo com o que the aconteceu, também sem ter repertório apropriado para isso. De acordo com a autora desse capítulo, o tempo médio que uma criança leva para revelar um abuso é de um ano e meio. Ao longo desse processo foi observado que as crianças geralmente fornecem indícios de que o abuso está ocorrendo. No entanto, muitas vezes os adultos 
não os percebem. A relevância dessas informações é muito grande para professores, pais, profissionais de saúde, juízes ou promotores que lidam direta ou indiretamente com crianças e adolescentes. Se tais agentes sociais tivessem um repertório de observação capaz de identificar esses indícios, aumentaria muito a probabilidade de intervir mais precocemente no abuso sexual de crianças e adolescentes, antes que eles se agravassem e, como ocorre na maioria dos casos, se tornassem algo de correção muito difícil, demorada, cara e com sofrimento para muitas pessoas. O livro de Williams e Araújo parece ajudar em muitos aspectos na detecção desses indícios e aumentar a probabilidade de que um repertório mais apurado de leitores possa ser desenvolvido e, dessa forma, aumentar a contribuição social desses tipos de agentes sociais em relação ao problema.

Identificar os comportamentos de crianças e adolescentes que sofrem abuso sexual foi um dos comportamentos ensinados a professores por meio de um projeto de prevenção de abuso sexual destinado a professores de escolas públicas. Esse projeto é apresentado no livro com o título "Professores como agentes de prevenção do abuso sexual infantil: detalhamento de um programa de capacitação" (autoria de Raquel de Faria Brino e Lúcia Cavalcanti Williams). Como crianças e adolescentes, geralmente, passam grande parte de seu dia na escola, professores e educadores deveriam desenvolver capacitação consistente para identificar e providenciar verificação de possíveis ou prováveis casos de abuso sexual com seus alunos. No Brasil, essa capacitação é cada vez mais necessária e urgente, principalmente pelo fato de professores e educadores não estarem preparados para lidar com esse fenômeno. De acordo com os estudos apresentados no livro "Prevenção do abuso sexual infantil: um enfoque interdisciplinar" fica evidente não só o despreparo, como também o constrangimento ou o temor de ter que lidar com tais situações por parte de vários tipos de agentes sociais que poderiam, muito precocemente, identificar situações de risco de abusos de tal ordem com crianças e adolescentes.

No capítulo "Intervenção escolar para prevenção do abuso sexual com estudantes pré-adolescentes e adolescentes" (autoria de Maria da Graça Saldanha Padilha e Lúcia Cavalcanti de Albuquerque Williams) são apresentadas informações relativas à prevenção do abuso sexual infantil em escolas. Tais informações possibilitam maior visibilidade a respeito da possibilidade de realizar intervenções profissionais simples capazes de prevenir a ocorrência do abuso ou diminuir o tempo de revelação desses abusos por parte das vítimas. Uma dessas intervenções é o ensino de uma cadeia comportamental que possibilita às crianças (ou adolescentes): a) reconhecer a aproximação não apropriada de um adulto; b) aprender a dizer "não" diante de situações de risco; c) deixar a situação com rapidez; e d) 
comunicar o incidente a alguém que possa auxiliar no enfrentamento dessa situação. Uma intervenção desse tipo, seguramente é mais barata, menos prejudicial, tem menos sofrimento e é menos complexa do que aquelas feitas após a ocorrência do abuso sexual.

Ainda que a prevenção (ou o comportamento de prevenir abusos sexuais) esteja destacada como um dos processos comportamentais centrais da obra, é possível afirmar que o livro trata preponderantemente de processos relativos à intervenção após a ocorrência do abuso sexual. Aprofundar os vários âmbitos de atuação profissional examinados por Rebelatto e Botomé (1991) e Stédile (1996), por exemplo, possibilitariam o desenvolvimento de uma ampla gama de comportamentos de agentes sociais em relação a mais do que apenas "resolver o problema que ocorreu ou tratar das pessoas que sofreram com o abuso sexual e suas decorrências", mas também a atenuar sofrimento, reabilitar pessoas em relação ao que foi prejudicado pelo abuso, prevenir abuso sexual, aperfeiçoar ou promover comportamentos que possibilitem eliminar esse problema da sociedade ou de uma parcela dela. O livro de William e Araújo destaca muitos aspectos que indicam a necessidade de capacitar agentes sociais para atuar em vários âmbitos de atuação para lidar melhor com a ocorrência ou probabilidade de ocorrência de abuso sexual de crianças e adolescentes. Vale a pena destacar o esforço que alguns autores têm feito no sentido de delimitar o conceito "prevenção" às intervenções que são realizadas antes de os problemas ocorrerem (NATIONAL RESEARCH COUNCIL AND INSTITUTE OF MEDICINE, 2009, por exemplo) e de forma a nunca ocorrerem no futuro (REBELATTO; BOTOMÉ, 1991; STÉDILE, 1996). Essa necessidade de delimitação das possibilidades de atuação de diferentes agentes sociais justifica-se pela necessidade de maiores esforços de pesquisadores e profissionais da área no desenvolvimento de medidas que impeçam que crianças e adolescentes sejam submetidos a esse tipo de violência, mais do que as socorram depois que tal violência já ocorreu. A capacitação para que diferentes agentes ou agências sociais identifiquem a probabilidade de ocorrência de abuso sexual é algo fundamental para lidar com maior eficácia social com esse tipo de problema e isso exige 0 desenvolvimento de repertórios mais elaborados que os existentes na sociedade. A obra de Williams e Araújo é uma importante contribuição para um trabalho significativo com esse tipo de problema na sociedade.

O livro "Prevenção do abuso sexual infantil: um enforque interdisciplinar" organizado por Lúcia C. de A. Willians e Eliane A. C. Araújo é, por tudo isso, uma importante fonte de informação para profissionais que trabalham direta ou indiretamente com crianças e adolescentes que sofreram esse tipo de violência. Assim como para aqueles que lidam com crianças e adolescentes em seu cotidiano 
profissional, principalmente quando há presença ou aumento dos aspectos que indicam risco de ocorrência desse tipo de problema - o que torna maior a probabilidade de essas crianças e adolescentes tornarem-se vítimas (potenciais, pelo menos) desse tipo de abuso. Os capítulos escritos por diferentes profissionais que lidam com esse problema (ou com a probabilidade de ocorrência) possibilitam (e exigem) um trabalho multidisciplinar indispensável para tratar de algo tão complexo quanto o abuso sexual de crianças e adolescentes. Sem dúvida, uma contribuição importante para aumentar os graus de clareza quanto às possibilidades de intervenção e prevenção da ocorrência de uma das violências menos denunciadas no mundo.

\section{Referências}

NATIONAL RESEARCH COUNCIL AND INSTITUTE OF MEDICINE. Preventing mental, emotional, and behavioral disorders among young people. Washington, DC: The National Academic Press, 2009.

REBELATTO, J. R.; BOTOMÉ, S. P. Fisioterapia no Brasil: fundamentos para uma ação preventiva e perspectivas profissionais. 2. ed. São Paulo: Manole, 1999.

STÉDILE, N. L. R. Prevenção em saúde: comportamentos profissionais a desenvolver na formação do enfermeiro. 1996. $229 \mathrm{f}$. Dissertação (Mestrado em Educação) - Programa de Pós-Graduação em Educação, Universidade Federal de São Carlos, São Carlos - SP, 1996.

\section{Endereço para correspondência \\ Luciana Cristina Assini \\ SPH Building, Valley Drive \\ University of Maryland - College Park, MD \\ 20742-2611 \\ Endereço eletrônico: lu_assini@hotmail.com}

\section{Sílvio Paulo Botomé}

Departamento de Psicologia - Centro de Filosofia e Ciências Humanas Universidade Federal de Santa Catarina - Campus Universitário - Trindade Florianópolis, Santa Catarina. CEP 88.040-970

Endereço eletrônico: botome@cfh.ufsc.br

Recebido em: 17/03/2011

Reformulado em: 18/08/2011

Aceito para publicação em: 18/08/2011

Acompanhamento do processo editorial: Deise Mancebo 


\section{Notas}

* Doutoranda no Programa de Pós-graduação em Saúde Pública na Universidade de Maryland - College Park, MD, EUA. Mestre em Psicologia pela Universidade Federal de Santa Catarina.

**Mestre em Psicologia, Doutor em Ciências Sociais, Professor Titular do Departamento de Psicologia da Universidade Federal de Santa Catarina e pesquisador do CNPq. 